\title{
Enterprise Architecture Meta Models for IT/Business Alignment Situations
}

\author{
Jan Saat \\ Institute of Information Management \\ University of St Gallen \\ St Gallen, Switzerland \\ jan.saat@unisg.ch
}

\author{
Ulrik Franke, Robert Lagerström, Mathias Ekstedt \\ Industrial Information and Control Systems \\ The Royal Institute of Technology (KTH) \\ Stockholm, Sweden \\ \{ulrikf, robertl, mek101\}@ics.kth.se
}

\begin{abstract}
Enterprise Architecture models can be used to support IT/business alignment. However, existing approaches do not distinguish between different IT/business alignment situations. Since companies face diverse challenges in achieving a high degree of IT/business alignment, a universal 'one size fits all' approach does not seem appropriate. This paper proposes to decompose the IT/business alignment problem into tangible qualities for business, IT systems, and IT governance. An explorative study among 162 professionals is used to distinguish four IT/business alignment situations, i.e. four clusters of IT/business alignment problems. These situations each represent the current state according to certain qualities and also the priorities for future development. In order to increase IT/business alignment, enterprise architecture meta models are proposed for each identified situation. One core meta model (to reflect common priorities) as well as situationspecific extensions are presented.
\end{abstract}

Keywords-Enterprise Architecture; IT/Business Alignment; Meta Modeling.

\section{INTRODUCTION}

IT/business alignment has been among the top priorities for IT executives for several years [31] [32] [33] [34]. Research on IT/business alignment can take a descriptive perspective (understanding of the alignment phenomena) or a prescriptive design perspective (construction of artifacts that support alignment). The amount of prescriptive research artifacts that address IT/business alignment problems is limited. Furthermore, such artifacts usually do not distinguish different problem contexts (e.g. industry, company size) or different goals (e.g. improving transparency, reducing inconsistencies, improving flexibility). As diverse problem situations require different design solutions, prescriptive research should provide situation-specific or at least adaptable solutions instead of 'one-size-fits-all' artifacts. Instruments of enterprise architecture (EA), such as models, have proven to be useful when addressing IT/business alignment problems [2] [44]. However, existing approaches do not consider the variety of situations, i.e. are not adaptable to different contexts and goals.

The descriptive contribution of the paper is the identification of as-is states for IT/business alignment. As IT/business alignment is a very widely used and 'fuzzy' term, goal decomposition is used to characterize IT/business alignment by qualities from the perspectives of IT systems, business, and IT governance, respectively. Furthermore, based on a survey among 162 EA professionals from Scandinavia and the German speaking countries, tailored meta models suitable for the typical situations identified are presented. These meta models serve as best practice templates for the modeling efforts of enterprises finding themselves in each of the typical situations found in the survey. This is the prescriptive design contribution.

The remainder of this paper is structured as follows: Section II explains conceptual foundations relevant for the proposed approach, as well as related work in the fields of EA and IT/business alignment. As meta models represent a core instrument of EA, special emphasis is put on approaches where meta models are utilized for IT/business alignment. In section III, IT/business alignment is addressed by considering qualities of IT systems, business, and IT governance. Section IV then briefly describes the setup and the analysis method of the survey, leading to the identification of four typical IT/business alignment situations. Based on the findings, situation specific meta models are presented in section V. The results are critically reflected upon in section VI, and section VII then concludes the paper.

\section{CONCEPTUAL FOUNDATION AND RELATED WORK}

To place the present contribution in a proper context, this section outlines some related work and important concepts. Three main research disciplines are covered: enterprise architecture, meta modeling, and IT/business alignment.

\section{A. Enterprise architecture}

EA has been proposed as an approach for managing the business and IT on a strategic level. EA targets a holistic and unified scope of an organization [45] [54]. This overarching perspective is also present in the ANSI/IEEE Standard 14712000 defining architecture as "the fundamental organization of a system, embodied in its components, their relationships to each other and the environment, and the principles governing its design and evolution" [15]. As a consequence of this wide scope, EA is typically not limited to IT, but also encompasses the relation and support of IT to the business. Thus, in many respects, EA can be seen as a tool for achieving alignment between business and IT.

If the joint scope of IT and business is one defining part of EA, its model-based methodology is another. As the name hints, architectural descriptions are central in EA. These 
descriptions include entities covering a broad range of phenomena, such as strategic aspects, organizational structure, business processes, software and data, as well as IT infrastructure [22] [28] [56]. A large number of EA frameworks have been proposed by the community, each detailing the kind of entities that should be part of the modeling effort. Some examples are [4] [28] [29] [37] [53].

Essentially, EA models serve the purpose of helping various stakeholders of the organization to document and thus understand the complex enterprise, analyze the properties of current and potential future scenarios, plan and design future scenarios and the road to get there, as well as communicating the current and future state of affairs to other stakeholders in the organization. Furthermore, by focusing on particular needs of decision-makers - modeling not for modeling's sake, but for particular purposes - EA can be used as a powerful decision-support tool [21].

\section{B. Meta models and meta modeling}

Meta models are a core part of enterprise architecture, ensuring semantic rigor, interoperability, and traceability [7] by stipulating the fundamental artifacts of business and IT as well as their interrelationships in a single aggregate model [56]. While some of the popular EA frameworks propose a meta model of their own [4] [28] [29] [37] [53], others are less meta model-centric e.g. [57]. However, whether explicit or implicit in architecture frameworks, meta models play an important role in all EA efforts by providing a common language for the enterprise.

In [23] [24], an approach to elicit concerns and information needs for information systems stakeholders is proposed. The goal is to derive a customized meta model from these concerns and needs. Using a five step process, the modeling requirements from the stakeholders are elicited, specified as viewpoints, and refined into meta model fragments which are then integrated into a comprehensive meta model. The approach presented is corroborated by a number of case studies.

In [21], another approach is described that departs not from stakeholders per se, but rather from their decisionmaking needs. Based on non-functional system qualities, inspired by the ISO-9126 standard [16] [17] [18], a number of meta models have been devised which are dedicated to the analysis of availability, security, interoperability, modifiability etc. The unique feature of this method is that it focuses on the causal relations that hold between the various meta model properties. Breakdowns into causal relations, as opposed to mere correlations, taxonomies or organizational hierarchies, are action guiding in the sense that they give advice on what measures are needed to improve availability, security, interoperability, modifiability etc. in an enterprise [26].

The two approaches outlined above are not mutually exclusive. In [27], a best-of-breed method combing the two is outlined.

\section{IT/business alignment and the role of enterprise architecture}

Since EA in many respects can be seen as tool for achieving alignment between business and IT, related work on the interrelation between these is presented in this subsection.

The framework proposed by Henderson and Venkatraman is widely applied and is generally considered to be a key reference strategic alignment model [13]. It contains four components needed for alignment assessment, viz. (1) business strategy, (2) IT strategy, (3) organizational infrastructure and processes, and (4) IT infrastructure and processes. The interactions of these four components along two dimensions, strategic integration and functional integration, form the state space of the model.

[30] developed a strategic alignment measurement tool based on detailed maturity models covering six distinct areas: (1) communications, (2) competence/value, (3) governance, (4) partnership, (5) technology scope, and (6) skills maturity. This work was later extended in [48] into the Strategic Alignment Maturity Assessment (SAMA).

Based on an empirical study [3] argues that IT/business alignment can only be achieved using a systematic change method. [3] proposes such a method, called Change Method Engineering, based on empirical findings of critical IT/business alignment success factors.

While none of the approaches described so far explicitly include the notion of EA in alignment, several other publications argue that EA indeed can be a valuable instrument to manage IT/Business Alignment. [2] propose what they call virtual decoupling to achieve IT/Business Alignment, i.e. an architecture-centric approach that divorces the external view of the architecture from its particular implementation. In doing so, the level of complexity is significantly reduced, thus enabling a more rational and less myopic approach to managing the alignment.

Moreover, the authors of [44] explicitly attempt to represent strategic IT/business alignment in enterprise architecture terms by proposing a meta model with the relevant entities and relations. They explain the criteria and the process for connecting Luftman's strategic alignment measures [30] with Zachman's Enterprise Architectural Framework [57]. However, this meta model is focused on strategic alignment and thus attempting to capture how well the IT organization is aligned with the business. It does not include any explicit guidelines for how to work with the information systems as such. In the present contribution, we try to dig deeper into this area and understand how information systems and their properties can be introduced when managing and analyzing alignment.

To summarize, the literature review shows that EA methods can contribute to the IT/business alignment challenge. However, when it comes to EA-driven IT/business alignment, no commonly accepted standards exist. This article aims at giving a state-of-the-practice snapshot and, on that basis, at providing suitable meta model fragments for representative as-is problem situations. 


\section{RESEARCH FRAMEWORK DECOMPOSING IT/BUSINESS ALIGNMENT}

As described above, IT/business alignment is a subject that has been widely covered in the literature, including work on EA enabled IT/business alignment. However, in order to get deeper insights into the alignment phenomenon, it is necessary to stipulate some definitions and operationalizations. In order to accomplish this, it is assumed that IT/business alignment can be understood as a design goal that companies strive for.

In order to be able to reach this IT/business alignment design goal, it is necessary to delineate the design parameters which are available to enterprise architects and decision makers. In order to enumerate these parameters, a number of qualities contributing to IT/business alignment are derived from existing research, standards and best practices. These qualities encompass (i) IT system qualities, (ii) business qualities, and (iii) IT governance qualities [21]. Figure 1 illustrates the approach conceptually. In particular, the jigsaw puzzle metaphor is intended to convey that no single set of qualities has primacy over any other. The role of the enterprise architects and decision makers is to make all the pieces fit together into a unified whole. IT/business alignment arises in the interaction of all the qualities and can be achieved only by adjusting all of them so that they fit each other.

In relation to the work of Henderson Venkatraman [13], the contribution of the present paper can be seen as an attempt to operationalize their strategic alignment model by saying something about the quality in those domains. We capture the $y$-axis (strategy - existing infrastructure) with asis and to-be respectively and we capture the $x$-axis with business vs IT systems and IT governance.

In the subsequent subsections, each of the three areas (i) IT system qualities, (ii) business qualities, and (iii) IT governance qualities - is detailed.

\section{A. IT system qualities}

The IT system qualities employed are based on the ISO 9126 standard [16] [17] [18]. These qualities have also been used in the EA research at the Royal Institute of Technology (KTH), perhaps most prominently in the book Enterprise Architecture - Models and analyses for information systems decision making [21].

Performance, or efficiency, as the ISO/IEC 9126 labels it, is a quality that characterizes how much work a system can perform and how fast. Performance is defined as the degree to which an IT system can meet its objective in terms of scalability and responsiveness [49].

Interoperability is described as the ability of two or more systems or components to exchange information and to use that information [14]. Interoperability is defined in terms of two kinds of data exchangeability, one related to data formats and the other related to a user's attempts to exchange data [19].

The availability of a system indicates how often a system is ready to deliver its services to its users. Post factum, availability is defined as the ratio between the system's time in service (uptime) and the total time (uptime plus downtime), i.e. a system's mean time to failure (MTTF) plus its mean time to repair (MTTR) [21].

The most common definition of IT system security is how well the system is capable of preserving the confidentiality, integrity and availability of its internal information [5] [6].

The usability of a system reflects how easy it is for a user to interact with and perform his or her tasks in the system. [16] defines usability as the understandability, learnability, operability and attractiveness of an IT system.

The accuracy of an IT system is measured by the degree to which it produces resulting data that is accurate and precise. This is determined by comparing the output value with the expected or "real" value. Precision, on the other hand, refers to how repeatable the output is, i.e. if the same input data gives the same output data [21].

The ease with which an IT system can be modified or adapted to a changed environment is referred to as maintainability, sometimes also called modifiability [14] [35]. Inspired by [35] maintainability is defined by five subqualities, namely flexibility, reusability, extensibility, portability, and integrability. These describe the different kinds of changes a system can be exposed to during its lifetime.

The suitability of an IT system is the degree to which the functionality of the system supports the system's intended work tasks. That is, a suitable system offers the functions specified in the requirements specification, and meets user expectations with regard to functionality. The definition of suitability used here is borrowed from [19]. This definition stipulates that a system's suitability is contingent upon the system's functional adequacy, functional implementation completeness, functional implementation coverage and functional specification stability.

\section{B. Business qualities}

The business qualities are based on a taxonomy originally presented in [9] [10], which is based on a literature consolidation of over 500 papers and 20 books. The particular subset of this taxonomy employed in the present survey is that used by [11].

Flexibility is defined as the degree to which the business processes and organizational units in a company have the ability to adapt to changes in market conditions/requirements, e.g. changed demand, political and economical factors.

Efficiency concerns the degree to which the business processes in a company exhibit short manufacturing times/lead times/cycle times/work times, much automation of work etc.

Effectiveness i.e. the degree to which the business processes in a company produce what the market demands and spend little time on paperwork and administration. 


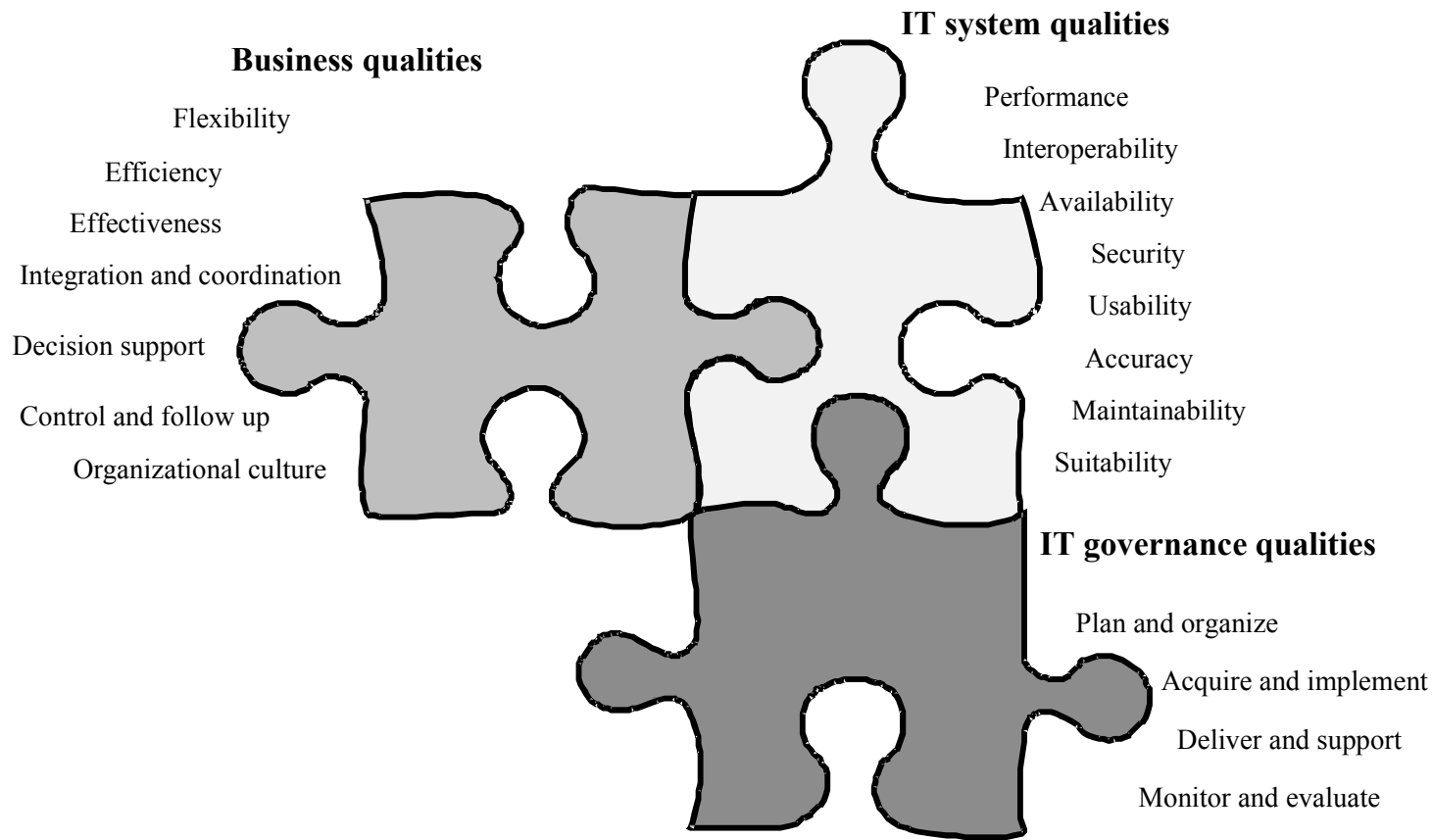

Figure 1. A conceptual view of an IT/business alignment operationalization.

Integration and coordination focuses on the degree to which the organizational units in a company have the ability to integrate and coordinate different parts of the organization, i.e. coordination of the production and the distribution department, of the sales and production planning departments etc.

Decision support deals with the degree to which an organizational unit has proper decision support, i.e. makes well-informed decisions, decisions are taken close to operations, decisions have high reliability and low uncertainty, decisions made are accepted by the organization etc.

Control and follow up is defined as the degree to which an organization has the ability to control and follow up work i.e. decisions are evaluated in retrospect, lessons learned are documented and re-used, new projects take previous experiences into account etc.

Organizational culture means to what degree the organizational culture in a company is appreciated by the people working at the company, i.e. there is a high job satisfaction and motivation, no negative stress, low numbers of sick leave etc.

\section{IT governance qualities}

The IT governance qualities are based on the four main processes of the well-known COBIT standard [20].

Plan and organize covers strategy and tactics, and concerns the identification of the way IT can best contribute to the achievement of the business objectives.

Acquire and implement is about realizing the ITstrategy, identifying, developing, or acquiring IT-solutions, as well as implementing and integrating these into the business processes.
Deliver and support is concerned with the actual delivery of required services, which includes service delivery, management of security and continuity, service support for users, and management of data and operational facilities.

Monitor and evaluate addresses performance management, monitoring of internal control, regulatory compliance and governance in order to keep or improve quality and compliance with control requirements.

Compared to the IT-system and business qualities, the IT governance qualities might prima facie look more like activities. However, this should be interpreted as an operationalization of IT governance qualities in terms of maturity of the IT processes. Thus, the IT processes per se are not our primary interest here.

\section{AN EMPIRICAL ANALYSIS OF IT/BUSINESS ALIGNMENT SITUATIONS}

The overall aim of the present study is to identify different as-is situations of IT/business alignment. In a second step, courses of action for future development are derived and supporting meta model fragments tailored specifically to suit the identified situations are provided in section $\mathrm{V}$.

An online survey was used for data collection. Prior to distribution, the survey was pretested with EA experts and valuable comments were received and addressed. Invitations were emailed to EA professionals in Sweden, Switzerland, Austria and Germany. The email addresses were condensed form the attendance lists of EA practitioner conferences that have been organized by the authoring institutions. Additionally a web link to the survey was posted on several EA community websites. Out of 1105 invitations sent, 92 emails bounced, 339 persons started and 174 persons 
completed the survey. The online survey was active for ten days (Sept. 11-21, 2009). The survey included a final question regarding the respondent's confidence with his or her answers. Twelve persons stated weak confidence so their answers were not further considered. A total of 162 completely filled-out surveys were thus subjected to the following analysis.

The questionnaire is comprised of four parts: Part one of the questionnaire contains questions regarding the background of the respondents such as industry, country, and company size as well as the respondent's role and involvement with EA. Respondents employed by a consulting company had the option to answer on behalf of a client company. This option was used by 43 respondents. The second part of the questionnaire has two sections. The first section contains questions addressing EA use for IT/business alignment and the importance and perceived maturity of IT/business alignment at the respondent's company. Section two contains more detailed questions related to IT/business alignment and the positioning of the IT department within the respondent's company. The third part of the questionnaire addresses the qualities regarding IT, business, and IT governance as presented in section III. For each quality one statement was posted and the respondents were asked to mark the actual (as-is) situation (degree of realization) and desired (to-be) situation (importance for future realization) on a five-point Likert scale (where 1 equals very low, 2 equals low, 3 equals medium, 4 equals high, and 5 equals very high). The final part of the questionnaire contains a question regarding the respondents' confidence regarding the answers as well as the possibility to submit questions and feedback to the authors.

Firstly, the data was examined by factor analysis in order to identify a limited number of factors with a large explanatory power. Second, these factors were used as input for a clustering procedure that groups the problem descriptions represented by the respondent's data into a small number of clusters with different characteristics. Third, based on the areas prioritized for the future (i.e. the to-be answers) of these respondents, meta model fragments are tailored to meet the modeling needs of the respective clusters, as seen in Figure 2.

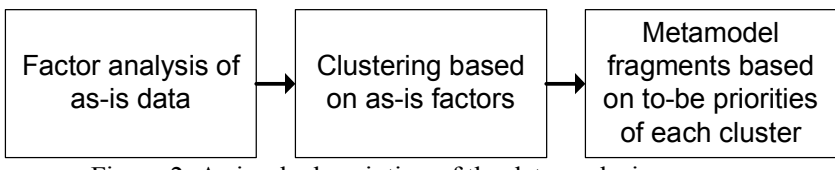

Figure 2. A simple description of the data analysis process.

A more thorough presentation of the data and the factor and cluster analysis is presented in [46]. The four situations found in the analysis are presented in the subsequent subsections.

\section{A. As-Is Situation A: technical quality biased}

The first situation (cluster) scores highest on the factor system quality orientation. Business planning issues are not prioritized high. The analysis shows that IT/business alignment is perceived to be an important issue. However, the degree of IT/business alignment in the respective company is regarded to be rather low. EA is not seen as valuable instrument for IT/business alignment.

\section{B. As-Is Situation B: business demand biased}

Contrary to as-is situation A, business-driven planning is the most important issue for situation (cluster) B. The experience of using EA instruments, such as models, processes, roles, and tools, is similar to situation A, yet fairly low with 2.5 to 4 years.

\section{As-Is Situation C: aligned innovation biased}

Situation (cluster) $\mathrm{C}$ focuses on characteristics of all three factors and delivers equally high scores for business and the IT-driven dimensions, while also considerably incorporating compliance aspects. In this situation, EA is considered to be a valuable instrument for IT/business alignment. This is underlined by top scores in years of EA instruments usage. In this cluster, EA instruments have been used for 6 (tools) to 8.5 (models) years on average. This justifies the assumption that organizational implementation and EA maturity in this situation are quite high.

\section{As-Is Situation D: compliance biased}

This situation (cluster) is compliance focused and business oriented. The situation is characterized by high perceived IT/business alignment and a fair history of EA usage (3.5 to almost 5 years). EA is regarded to be of valuable assistance in achieving IT/business alignment.

\section{META MODELS FOR IT/BUSINESS ALIGNMENT}

Meta models are a core concept of EA, describing the fundamental artifacts of business and IT. These high level models provide a common language and a clear view on the structure of and dependencies between relevant parts of the organization [1]. In essence, this is accomplished by providing a template for models: the permissible entities and their connections are prescribed by the meta model, so that all models based upon it are coherent. In this way, the meta model enforces semantic rigor among the models subsequently created in its image. Such rigor is a precondition for successful communication and documentation.

Meta models used for EA analysis typically also have attributes belonging to each entity [21]. These attributes correspond to qualities of interest. For example, an entity such as IT system can have several attributes, such as Availability, Security, and Maintainability. Analogously to the case of entity relations, a meta model can prescribe attribute relations. For example, the availability of an IT system can be prescribed to depend upon the availability of its constituent subsystems, e.g. a computer upon its hard drive and motherboard. In this way, the entity relations prescribed by a meta model can be made to correspond to a breakdown into causal relations. This enables predictions and model-based recommendations, as described for instance in [26].

However, creating appropriate meta models for such causal EA analysis poses some particular difficulties. First, a 
great number of aspects influence system properties. Second, the aspects are intertwined in a complex manner. Expressing this requires a meta model augmented with a suitable description language [21], and also a structured method to accurately depict the causalities [26]. However, these subjects cannot be pursued in depth here.

Instead, the present goal is to provide suitable meta models for each of the four as-is situations identified using clustering analysis in the previous section. These meta models will then serve as a kind of best practice templates for the modeling efforts of enterprises finding themselves in each of the situations.

TABLE I. presents the qualities that in their to-be situation were prioritized (on average) between high and very high by all four as-is situations.

TABLE I. ALL FOUR CLUSTERS PRIORITIZED THE FOLLOWING QUALITIES HIGH OR VERY HIGH IN THEIR TO-BE SITUATION.

\begin{tabular}{|l|r|}
\hline \multicolumn{2}{|c|}{ Top qualities for all four as-is situations } \\
\hline \multirow{4}{*}{ IT system } & Interoperability \\
\cline { 2 - 2 } & Availability \\
\cline { 2 - 2 } & Security \\
\cline { 2 - 2 } & Usability \\
\cline { 2 - 2 } Business & Accuracy \\
\cline { 2 - 2 } & Efficiency \\
\hline
\end{tabular}

Since all four as-is situations did prioritize these seven qualities as high or very high, these qualities will be the focus of the core meta model. For each situation, there is an additional add-on meta model fragment with highly prioritized qualities augmenting the core meta model.

Figure 3 shows our suggestion on a core meta model, described as a UML class diagram [42]. It includes the entities and entity relations taken from [43] that are related to the attributes in TABLE I. In addition, it includes two or three attributes that have a strong causal relation to each of the seven qualities. This explains why the core meta model contains some more entities than just the very fundamental ones derived from the prioritized qualities.

In the lower right corner of the meta model depicted in Figure 3, the availability attribute of an application has been highlighted. Attached to it is a very simple graphical representation, hinting towards its causal relationship. In this case, a fault tree is used to illustrate that the availability of a particular application hinges upon the software it is composed of, and upon the hardware it runs on. The availability of this hardware itself depends upon that of its sub-components. While the depicted availability relations are straightforward, a fuller depiction of the causal relations pertaining to this meta model would be considerably more complex. For instance, the availability attribute of a certain application would also depend upon the attributes of process entities such as maintenance and emergency support, which replace faulty components and fix other errors.

Needless to say, a complete model of the causal relations for all these attributes is beyond the scope of this article. For more comprehensive treatments on causal architectural analyses of system interoperability see [21] [39] [55], system availability see [8] [21] [40] system security see [21] [39] [50] [51] [52], system usability see [21] [39], system accuracy see [21] [38] [41], business efficiency see [9] [11] [12], and business effectiveness see [9] [11] [12].

TABLE II. THE TOP PRIORITIZED QUALITIES FOR AS-IS SITUATIONS A, B, C, AND D.

\begin{tabular}{|c|c|c|c|c|c|}
\hline \multicolumn{2}{|c|}{ Qualities / as-is situation } & \multirow{2}{*}{$\frac{\text { Situation A }}{\mathrm{X}}$} & \multirow[t]{2}{*}{ Situation B } & \multirow{2}{*}{$\frac{\text { Situation C }}{\mathrm{X}}$} & \multirow{2}{*}{$\frac{\text { Situation D }}{\mathrm{X}}$} \\
\hline \multirow{3}{*}{ IT system } & Performance & & & & \\
\hline & Maintainability & $\mathrm{X}$ & & $\mathrm{X}$ & $\mathrm{X}$ \\
\hline & Suitability & $\mathrm{X}$ & & $\mathrm{X}$ & $\mathrm{X}$ \\
\hline \multirow{5}{*}{ Business } & Flexibility & & & $\mathrm{X}$ & \\
\hline & Integration and Coordination & & $\mathrm{X}$ & $\mathrm{X}$ & \\
\hline & Decision Support & & & $\mathrm{X}$ & $\mathrm{X}$ \\
\hline & Control \& Follow Up & & & $\mathrm{X}$ & \\
\hline & Organizational Culture & & & $\mathrm{X}$ & \\
\hline \multirow{4}{*}{$\underset{\text { organization }}{\text { IT }}$} & Plan \& Organize & & $\mathrm{X}$ & $\mathrm{X}$ & $\mathrm{X}$ \\
\hline & Acquire \& Implement & & & $\mathrm{X}$ & $\mathrm{X}$ \\
\hline & Deliver \& Support & $\mathrm{X}$ & & $\mathrm{X}$ & $\mathrm{X}$ \\
\hline & Monitor \& Evaluate & & & $\mathrm{X}$ & $\mathrm{X}$ \\
\hline
\end{tabular}




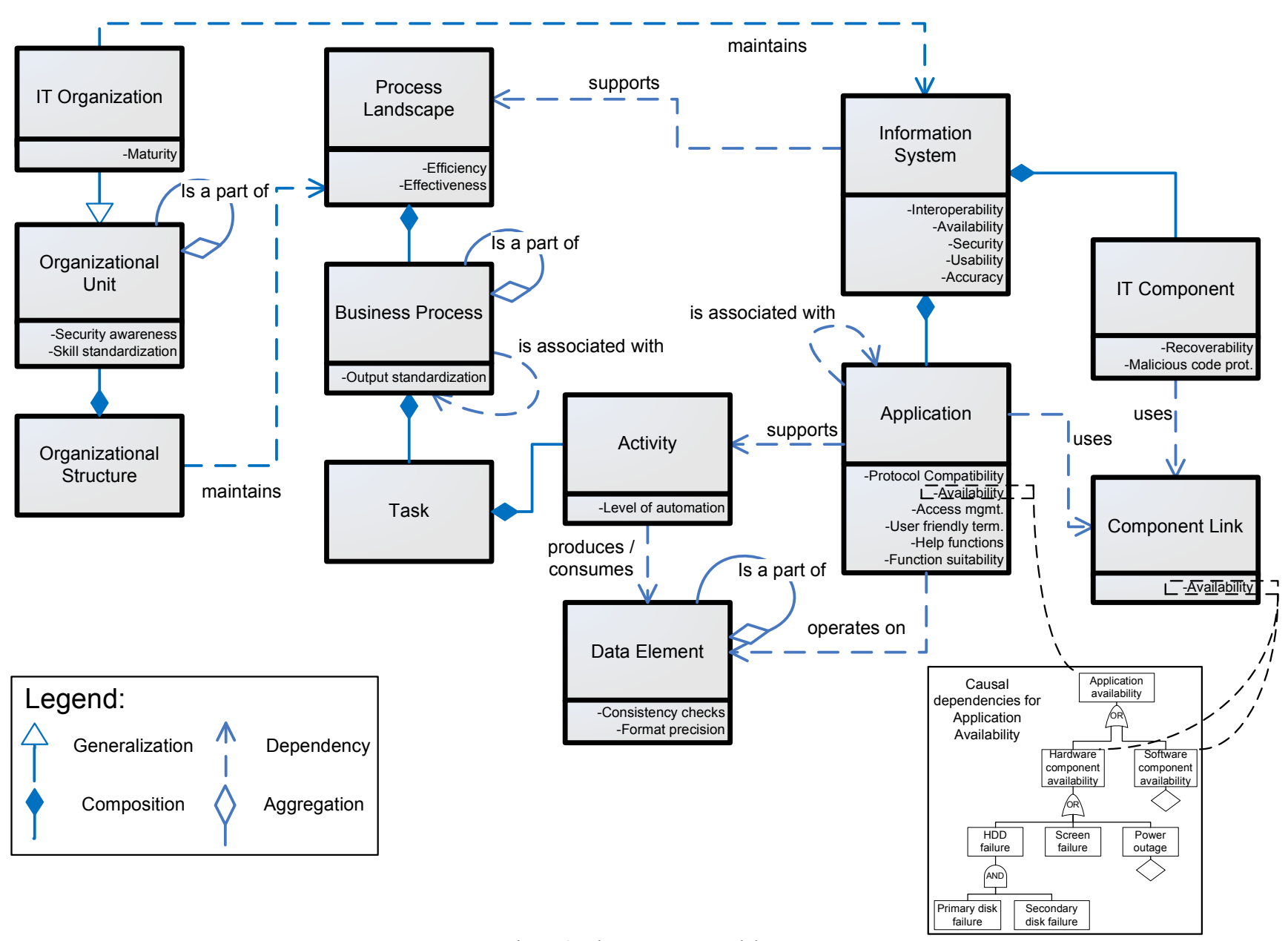

Figure 3. The core meta model.

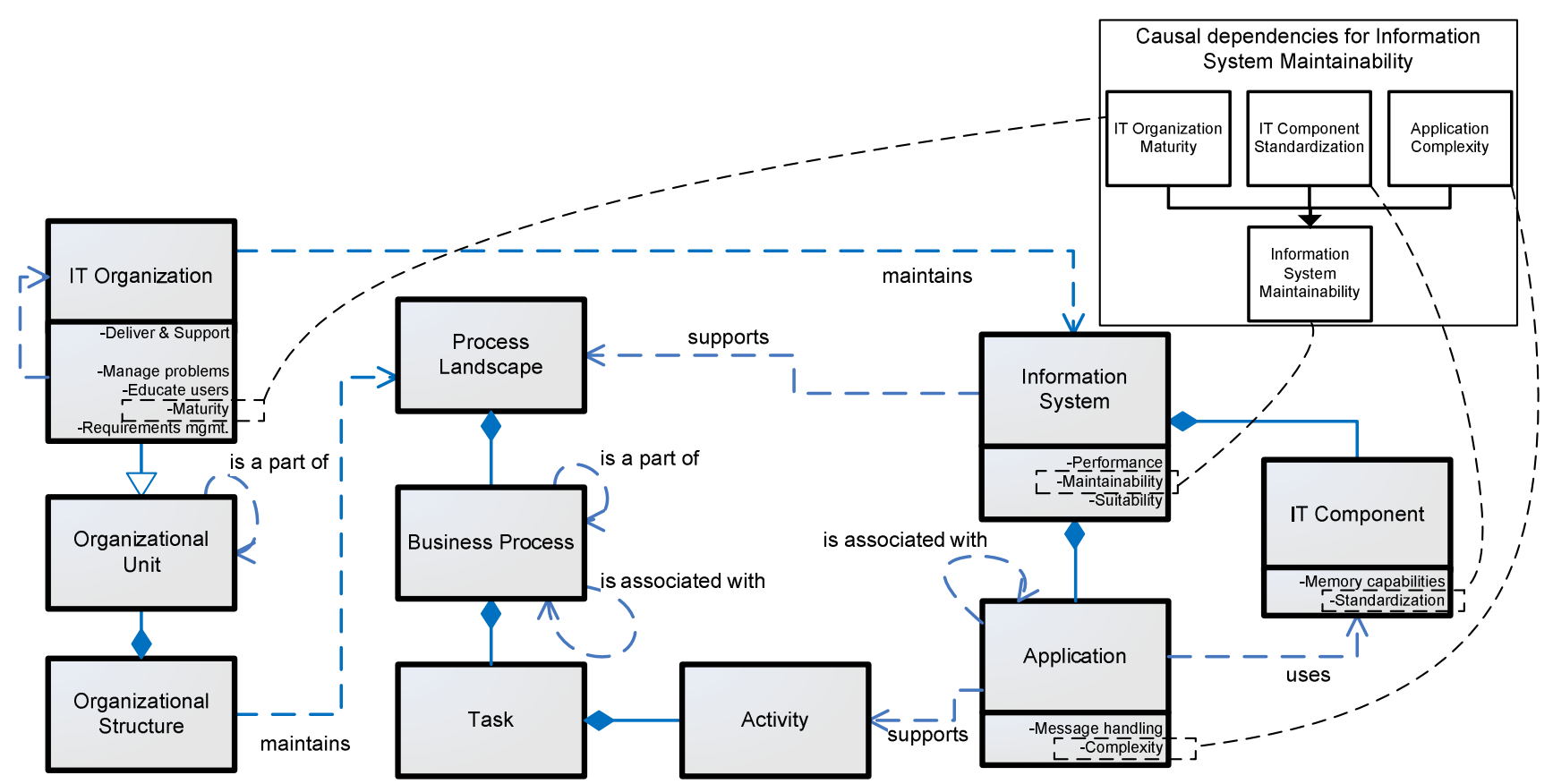

Figure 4. A meta model fragment for as-is situation A based on its prioritized qualities. 


\section{A. Meta model fragment add-ons for as-is situation $A, B, C$, and $D$}

Besides the core meta model presented in Figure 3, the respondents in as-is situation A prioritized the qualities in TABLE II. as high or very high in their to-be situation.

Thus, a meta model add-on for as-is situation A could look like the example in Figure 4.

In the upper right corner of Figure 4, a small exemplifying casual network is depicted in order to illustrate what attributes of the meta model fragment for situation A causally affect the information system maintainability. The attributes chosen to illustrate this are IT organization maturity, IT component standardization, and application complexity. Besides these three attributes there are additionally five attributes affecting information system performance, suitability, or IT organization deliver and support. These are only appropriate example attributes. For a more comprehensive treatment of system performance see [21][25][26], system suitability see [9] [39], and the IT organization's delivery and support see [47].

TABLE II. also presents as-is situations B, C, and D's top prioritized qualities. For each such a set of qualities, a meta model fragment add-on for the core meta model can be created just like the one presented for as-is situation A above.

\section{DISCUSSION}

The descriptive part of this paper identifies situations for IT/business alignment while the prescriptive part, the contribution of this paper, is the proposal of meta models for the identified situations.

To the industrial practitioner, the present paper assists the enterprise modeling effort. If a given enterprise can properly identify itself with one of the four states identified, the meta models presented in section $\mathrm{V}$ can serve as inspiration to obtain adequate model types with suitable elements and attributes.

To the EA tool industry, the present paper hints to potential new features or products. A tool incorporating the provided meta models would give a qualitative support to the user's modeling effort. The current market for EA tools does not explicitly consider different situations of customers. While some products offer customizable meta models, the methodological support on how to identify the company situation is rather elementary [36].

To the scientific community, the presented approach combines a novel way to address the goal of IT/business alignment by considering tangible qualities of IT systems, business, and IT governance. This may improve the creation of goal oriented artifacts in design-oriented research. Furthermore, the paper contributes to the discussion on situational artifact construction.

The data set consists of perceptions from individuals, where several completed surveys may originate from the same company. Therefore the results represent aggregated subjective responses that are suitable to derive trends within the presented situations. Due to the sample size a fair representation of trends within the results can be assumed.
The survey conducted only generates a snapshot of the investigated companies and design problems. The resulting meta models can thus be said to represent state of the practice instances. However, no correlation to the successrate of the companies involved has been made. It remains for further research to identify whether particular success factors can be discerned, thus enabling even more powerful modeling recommendations.

\section{CONCLUSION}

This paper argues that EA models can be used to support IT/business alignment. Since most companies face different challenges regarding the goal of achieving a high degree of IT/business alignment, a 'universal' approach does not seem suited to solve these issues. While existing approaches do not distinguish different situations of IT/business alignment, this paper presents an approach to creating situation-based solutions. Therefore IT/business alignment is addressed by considering tangible qualities for business, IT systems, and IT governance. An explorative study among 162 EA professionals is used to distinguish four different IT/business alignment situations. These situations each represent the current state described by different qualities and also influenced by the priorities for future development. In order to support the development towards IT/business alignment, EA meta models for the identified situations are created.

Future research activities in this area follow two branches. Firstly, from a situational method engineering perspective investigations on transformation paths should be conducted. Therefore the data set can be used to determine how the identified as-is situations can be transformed into their corresponding to-be situations. The presented meta models provide first insights for this. Secondly, the presented meta models can be further extended with causal relations and attributes in order to gain further insights on the impact that different qualities of IT systems, business, and IT governance have on each other and on IT/business alignment.

\section{ACKNOWLEDGMENT}

The authors would like to express their gratitude to Robert Winter for his valuable input to the article, and to the survey participants for taking the time to answer.

\section{REFERENCES}

[1] Aier, S., Kurpjuweit, S., Saat, J., Winter, R., Enterprise Architecture Design as an Engineering Discipline, in: AIS Transactions on Enterprise Systems, 1, 2009, No. 1, pp. 36-43

[2] Aier, S., Winter, R., Virtual Decoupling for IT/Business Alignment Conceptual Foundations, Architecture Design and Implementation Example, in: Business \& Information Systems Engineering, 51, 2009, No. 2, pp. 150-163

[3] Baumöl, U., Methodenkonstruktion für das Business-IT-Alignment, in: Wirtschaftsinformatik, 48, 2006, No. 5, pp. 314-322

[4] Department of Defense Architecture Framework Working Group, DoD Architecture Framework, version 1.5, Department of Defense, USA, 2007

[5] Dhillon, G., Backhouse, J., Information System Security Management in the New Millennium, in: Communications of the ACM, 43, 2000, No. 7 , 
[6] Ferraiolo, D., Kuhn, R., Role-Based Access Control, 1992, pp. 554563

[7] Franke, U., Ullberg, J., Sommestad, T., Lagerström, R., Johnson, P., Decision Support oriented Enterprise Architecture Metamodel Management using Classification Trees, Enterprise Distributed Object Computing Conference Workshops, EDOCW, September, 2009.

[8] Franke, U., Johnson, P., König, J., Marcks von Würtemberg, L., Availability of enterprise IT systems - an expert-based Bayesian model, Proc. Fourth International Workshop on Software Quality and Maintainability (WSQM 2010), Madrid, March 2010

[9] Gammelgård, M., Business Value Assessment of IT Investments - An Evaluation Method Applied to the Electrical Power Industry, Doctoral Thesis, Royal Institute of Technology (KTH), Stockholm, Sweden, 2007

[10] Gammelgård, M., Ekstedt, M., Gustafsson, P., A Categorization of Benefits From IS/IT Investments, Poceedings of the 13th European Conference on Information Technology Evaluation, ECITE 2006, Genoa, 28.09.2006, Academic Conferences International, 2006,

[11] Gustafsson, P., Franke, U., Höök, D., Johnson, P., Quantifying IT impacts on organizational structure and business value with Extended Influence Diagrams, First IFIP WG 8.1 Working Conference: The Practice of Enterprise Modeling (PoEM 2008), Stockholm, Springer, 2008, pp. 138-152

[12] Gustafsson, P., Höök, D., Ericsson, E., Lilliesköld, J., Analyzing IT Impacts on Organizationl Structure -- A Case Study, August, 2009,

[13] Henderson, J. C., Venkatraman, N., Strategic Alignment: Leveraging Information Technology for Transforming Organizations, in: IBM Systems Journal, 38, 1999, No. 2/3, pp. 472-484

[14] IEEE, IEEE Standard Glossary of Software Engineering Technology, The Institute of Electrical and Electronics Engineers, 1990

[15] IEEE, IEEE Recommended Practice for Architectural Description of Software Intensive Systems (IEEE Std 1471-2000), IEEE Computer Society, New York, NY, 2000

[16] ISO/IEC, Software engineering - Product quality - Part 1: Quality model, ISO/IEC TR 9126--1:2001(E), International Organization for Standardization, 2001

[17] ISO/IEC, Software engineering - Product quality - Part 2: External metrics, ISO/IEC TR 9126--2:2003(E), International Organization for Standardization, 2003a

[18] ISO/IEC, Software engineering - Product quality - Part 3: Internal metrics, ISO/IEC TR 9126--3:2003(E), International Organization for Standardization, 2003b

[19] ISO/IEC, ISO/IEC 42010:2007 - Systems and software engineering Recommended practice for architectural description of softwareintensive systems, ISO, 2007

[20] ITGI, IT Governance Institute: Cobit 4.1, IT Governance Institute, Rolling Meadows, 2007

[21] Johnson, P., Ekstedt, M., Enterprise Architecture: Models and Analyses for Information Systems Decision Making, Studentlitteratur, 2007

[22] Jonkers, H., Lankhorst, M. M., Doest, H. W. L., Arbab, F., Bosma, H., Wieringa, R. J., Enterprise architecture: Management tool and blueprint for the organisation, in: Information Systems Frontiers, 8, 2006, No. pp. 63-66

[23] Kurpjuweit, S., Winter, R., Viewpoint-based Meta Model Engineering, St. Goar, 08.10.2007, 2007, pp. 143-161

[24] Kurpjuweit, S., Winter, R., Concern-oriented Business Architecture Engineering, Proceedings of the 24th Annual ACM Symposium on Applied Computing, Honolulu, HI, 08.03.2009, 2009,

[25] Lagerström, R., Analyzing System Maintainability using Enterprise Architecture Models, in: Journal of Enterprise Architecture, 3, 2007, No. 4, pp. 33-42

[26] Lagerström, R., Franke, U., Johnson, P., Ullberg, J., A method for creating enterprise architecture metamodels - applied to systems modifiability analysis, in: International Journal of Computer Science and Applications, 2009, Volume VI, pp. 89-120

[27] Lagerström, R., Saat, J., Franke, U., Aier, S., Ekstedt, M., Enterprise Meta Modeling Methods - Combining a Stakeholder-Oriented and a Causality-Based Approach, Enterprise, Business-Process and Information Systems Modeling, Proceedings of the 10th International Workshop BPMDS and 14th International Conference EMMSAD at CAiSE 2009, Amsterdam, 08.06.2009, Springer, LNBIP 29, 2009b,

[28] Lankhorst, M., Enterprise Architecture at Work: Modelling, Communication and Analysis, Springer, Berlin et al., 2005

[29] Lankhorst, M., Proper, E., Jonkers, H., The Architecture of the ArchiMate Language, Enterprise, Business-Process and Information Systems Modeling, Amsterdam, 09.06.2009, Springer, LNBIP 29, 2009 ,

[30] Luftman, J. N., Assessing Business-IT Alignment Maturity, in: Communications of the Association for Information Systems (AIS), 4, 2000, No. 14, pp. $1-50$

[31] Luftman, J. N., Key Issues for IT Executives 2004, in: MISQ Executive, 4, 2005, No. 2, pp. 269-285

[32] Luftman, J. N., Kempaiah, R., Key Issues for IT Executives 2007, in: MISQ Executive, 7, 2008, No. 2, pp. 99-112

[33] Luftman, J. N., Kempaiah, R., Nash, E., Key Issues for IT Executives 2005, in: MISQ Executive, 5, 2006, No. 2, pp. 81-99

[34] Luftman, J. N., Kempaiah, R., Rigoni, E. H., Key Issues for IT Executives 2008, in: MISQ Executive, 8, 2009, No. 3, pp. 151-159

[35] Matinlassi, M., Niemelä, E., The Impact of Maintainability on Component-based Software Systems, 2003,

[36] Matthes, F., Buckl, S., Leitel, J., Schweda, C. M., Enterprise Architecture Management Tool Survey 2008, Software Engineering for Business Information Systems (SEBIS) Ernst DenertStiftungslehrstuhl Chair for Informatics 19 TU München, München, 2008

[37] Ministry of Defence, MOD Architecture Framework version 1.2.003, Ministry of Defence, UK, 2008

[38] Närman, P., Johnson, P., Ekstedt, M., Chenine, M., König, J., Enterprise Architecture Analysis for Data Accuracy Assessments, September, 13, 2009,

[39] Närman, P., Johnson, P., Nordström, L., Enterprise Architecture: A Framework Supportin[39]g System Quality Analysis, 2007,

[40] Närman, P., Johnson, P., Robert, L., Franke, U., Ekstedt, M., Data Collection Prioritization for Software Quality Analysis, April, 2008a,

[41] Närman, P., Schönherr, M., Johnson, P., Ekstedt, M., Chenine, M., Using Enterprise Architecture Models for System Quality Analysis, 12th IEEE International EDOC Conference (EDOC 2008), Munich, 2008b, pp. 14-23

[42] Oestereich, B., Die UML-Kurzreferenz für die Praxis - kurz, bündig, ballastfrei, Oldenburg, München, 2001

[43] Österle, H., Winter, R., Höning, F., Kurpjuweit, S., Osl, P., Business Engineering - Core-Business-Metamodell, in: WISU - Das Wirtschaftsstudium, 36, 2007, No. 2, pp. 191-194

[44] Plazaola, L., Flores, J., Silva, E., Vargas, N., Ekstedt, M., An Approach to Associate Strategic Business-IT alignment Assessment to Enterprise Architecture, Fifth Conference on Systems Engineering 2007 (CSER2007), New Jersey, Stevens Institute of Technology, 2007 ,

[45] Rohloff, M., Framework and Reference for Architecture Design, 14th Americas Conference on Information Systems (AMCIS 2008), Toronto, 2008,

[46] Saat, J., Franke, U., Lagerström, R., Ekstedt, M., Winter, R., Analysis of IT/Business Alignment Situations as a Precondition for the Design and Engineering of Situated IT/Business Alignment Solutions, submitted manuscript, 2010.

[47] Simonsson, M., Predicting IT Governance Performance: A Method for Model-Based Decision Making, Doctoral Thesis, Royal Institute of Technology (KTH), Stockholm, Sweden, 2008 
[48] Sledgianowski, D., Luftman, J. N., IT-Business Strategic Alignment Maturity: A Case Study, in: Journal of Cases on Information Technology, 7, 2005, No. 2, pp. 102-120

[49] Smith, C. U., Williams, L. G., Performance Solutions: A Practical Guide to Creating Responsive, Scalable Software, Addison Wesley, 2001

[50] Sommestad, T., Ekstedt, M., Enterprise Architecture Models for Cyber Security Analysis, 2009,

[51] Sommestad, T., Ekstedt, M., Johnson, P., Cyber Security Risks Assessment with Bayesian Defense Graphs and Architectural Models, 2009a,

[52] Sommestad, T., Ekstedt, M., Nordström, L., Modeling security of power communication systems using defense graphs and influence diagrams, in: IEEE Transactions on Power Delivery, 2009b, No.
[53] The Open Group, TOGAF (The Open Group Architecture Framework) Version 9, 2009

[54] Tyler, D. F., Cathcart, T. P., A structured Method for Developing Agile Enterprise Architectures, Norfolk, Virginia, USA, July 19-20 2006, 2006, pp. 1-8

[55] Ullberg, J., Lagerström, R., Johnson, P., A Framework for Service Interoperability Analysis using Enterprise Architecture Models, IEEE International Conference on Services Computing (SCC 2008), Beijing, China, 2008,

[56] Winter, R., Fischer, R., Essential Layers, Artifacts, and Dependencies of Enterprise Architecture, in: Journal of Enterprise Architecture, 3, 2007, No. 2, pp. 7-18[16][11][39]

[57] Zachman, J. A., A Framework for Information Systems Architecture, in: IBM Systems Journal, 26, 1987, No. 3, pp. 276-292 